\title{
Modification of Steel Surface Using the Laser Energy Olga Chudina
}

\author{
Olga Chudina \\ Moscow Automobile and Road Construction State Technical University (MADI), Moscow, Russia \\ Email: chudina madi@mail.ru
}

Received 26 March 2014; revised 25 April 2014; accepted 24 May 2014

Copyright (C) 2014 by author and Scientific Research Publishing Inc.

This work is licensed under the Creative Commons Attribution International License (CC BY). http://creativecommons.org/licenses/by/4.0/

(c) (i) Open Access

\begin{abstract}
The article is devoted to surface hardening of steels by alloying with the use of laser energy. Two combined technologies were proposed: first-laser alloying by nitride-forming elements followed by nitriding, and second-the local laser alloying followed by metallization in atmosphere of ammonia. It is shown that laser alloying in continuous radiation forms a layer with a homogeneous fine-grained structure with thickness of 600 microns. The subsequent nitriding increases the microhardness of the surface layer of low-carbon steels to $20,000 \mathrm{MPa}$, increases wear-resistance in a 3 - 15 times and crack resistance in a 1.5 times. Two-stage technology of metallization allows getting diffusion layer on the surface of steels with the thickness, which is 1.5 - 2 times higher than after traditional metallization. In addition, this method of surface modification can significantly reduce the temperature of diffusion metallization and reduce the processing time to 3 hours. The optimal regimes of both technologies, which provide homogeneous multiphase diffusion layers with high hardness and wear resistance, were determined.
\end{abstract}

\section{Keywords}

Laser Alloying, Nitriding, Metallization, Diffusion Layer

\section{Introduction}

High Physical and Mechanical properties of the machine parts can be obtained through a targeted surface modification using laser energy [1].

Surface modification is carried out by laser alloying with different elements and their compositions from suspensions, which is containing powder of alloying element and an organic binder (glue or nail). The laser beam non-contact, fast and strictly dosed transfers energy to the surface of the material. The surface with alloying suspension melts, binder evaporates and the alloying component introduces into surface, mixes with the base material, and is more or less uniformly distributed inside the melting zone and then crystallizes. 
Alloying process can be carried out using a pulsed or continuous radiation. The difference is that, when using a pulse radiation on the surface of treated metal zones as circular "spots" are forming, whose thickness is about 150 - 300 microns, and with continuous radiation "tracks" are forming, their thickness can be more than 900 microns [2].

However, currently this method of surface modification is not widely used in the industry. This is due to the fact that large temperature gradient on the border between the base metal and the zone of laser treatment tensile stresses are formed, which during exploitation cause cracking and destruction of the parts on brittle mechanism [3] [4].

It can be eliminated by heating, but the level of strengthening achieved after laser alloying considerably reduced [5].

In this connection, finding ways to increase efficiency of the laser energy in order to increase the strength is an actual problem. We suggested that the solution of this problem is possible through the development of combined processes, which combine laser treatment with other chemical and heat treatment of metals.

\section{Methods of Researches and Materials}

In this paper we investigated steels $20(0.2 \% \mathrm{C}), 40 \times(0.4 \% \mathrm{C}, 1 \% \mathrm{Cr})$ and pure iron as a model material. For alloying, we used powders of $\mathrm{Cr}, \mathrm{V}, \mathrm{Mo}, \mathrm{W}, \mathrm{Nb}$ and Al. Alloying was carried out on test samples in continuous CO-2 laser of type LOK-2M with power $1 \mathrm{~kW}$ power and at a rate laser beam moving from 2 to $30 \mathrm{~mm} / \mathrm{sec}$. Alloying in a pulsed regime with a laser, "Kvant-16" of power up to $24 \mathrm{~J}$. Alloying of coating carried out based on a $10 \%$ solution of glue in acetone, the amount of which controlled by a weight method. Nitriding carried out in an ammonia atmosphere under reduced pressure in an industrial furnace. The duration varied from 3 to 30 hours at a temperature of $570^{\circ} \mathrm{C}$. The metallographic analysis was performed on the optical microscope "Neophot-21" with an increase up to $\times 1000$. Concentration of alloying elements in the laser zones was determined by electron microprobe analyzer "Superprobe-704" with continuous scanning probe. The distribution of alloying elements and nitrogen in the modified zones were determined on the scanning analyzer "Link-system". The phase composition determined by X-ray method on the "Dron-3". Residual stresses of the surface layer we determined using the method of multiple inclined shootings.

\section{Discussion of the Results}

Modifying of steel surface in pulsed radiation of the laser beam is very small-3 - $5 \mathrm{~ms}$, and the processes of mass transfer and convective mixing is not completed, so the alloying element there is unevenly distributed (Figure 1). In continuous radiation surface warms more slowly and a more homogeneous structure is formed (Figure 2, Figure 3(a) and Figure 3(b)). However, the degree of homogeneity and the structure depends on the speed of the laser beam. The lower the speed of the beam, the more homogeneous structure on the metal surface formed.

In this paper, we consider two combined technologies of strengthening steels using laser treatment.

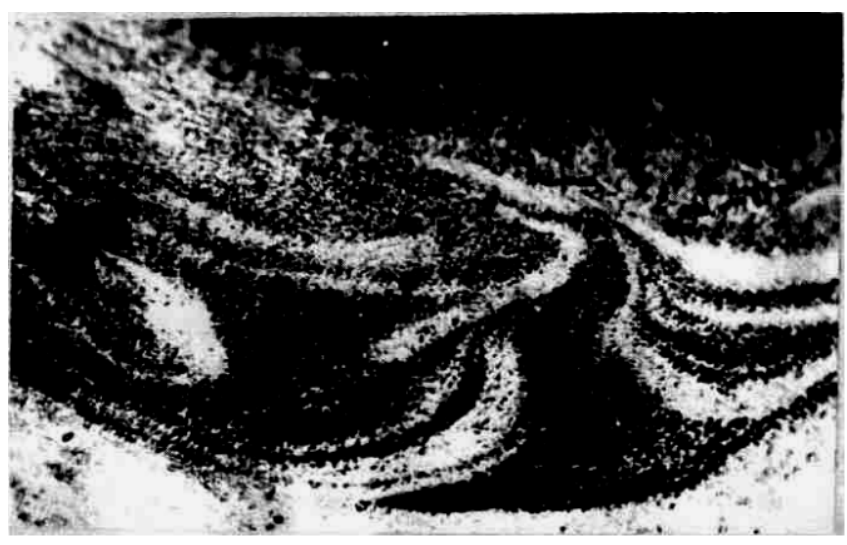

Figure 1. Microstructure of carbon steel, after laser alloying by $\mathrm{Nb}$ in pulsed radiation, $\times 750$. 


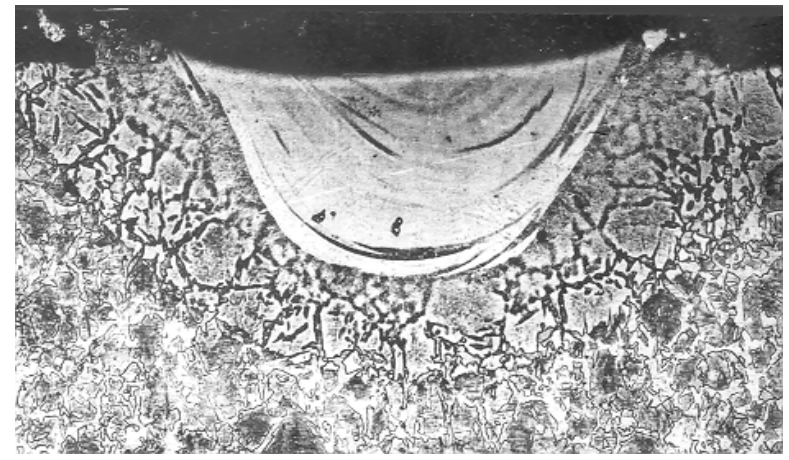

Figure 2. The microstructure of steel $(0.45 \% \mathrm{C})$, after laser alloying by $\mathrm{Mo}$ in continuous radiation, $\mathrm{P}=1 \mathrm{~kW}, \mathrm{~V}=15$ $\mathrm{mm} / \mathrm{s}, \times 100$.

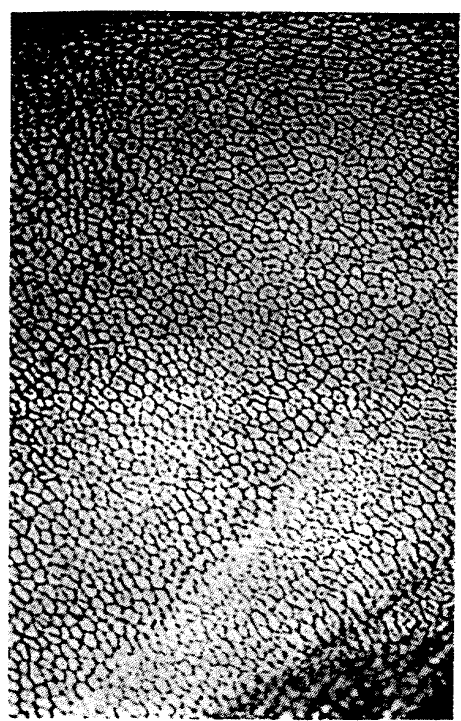

(a)

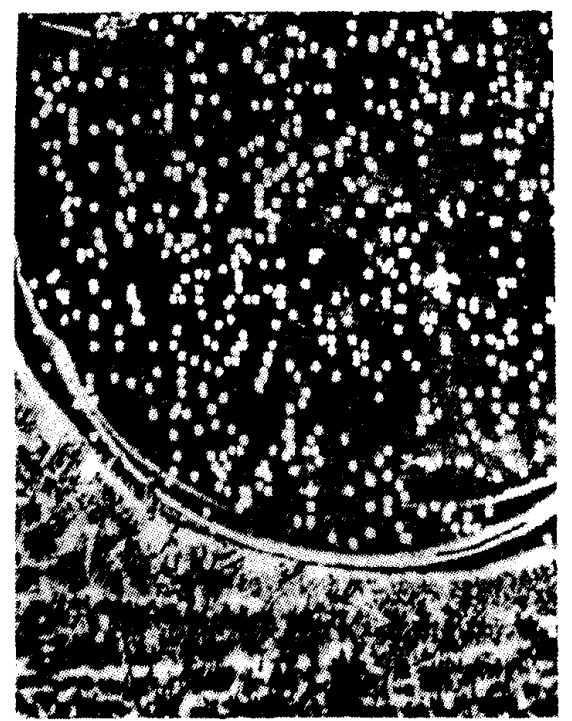

(b)

Figure 3. Microstructure of steel $20(0.2 \% \mathrm{C})$ after laser alloying by $\mathrm{Cr}$ in continuous radiation, $\mathrm{P}=1 \mathrm{~kW}, \mathrm{~V}=10 \mathrm{~mm} / \mathrm{s}, \times 800(\mathrm{a})$, distribution of $\mathrm{Cr}$ in the alloyed zone, $\times 100$ (b).

\subsection{Laser Alloying of Steels by Nitride-Forming Elements Followed by Nitriding}

We investigated the effect of combined treatment on the formation of modified layers on steels with $0.2 \%$ to $1.0 \% \mathrm{C}$. The technological parameters for laser alloying include the radiation power density and the amount of the coating deposited on the surface to be treated. With an increase of the radiation power density, the thickness of the alloyed zone increases for all the investigated alloying elements: and the zones alloyed with aluminum always have the greatest thickness while the zones saturated with molibdenum always have the smallest thickness. The amount of saturating coating deposited on the surface to be treated has a substantial effect on the thickness of the alloyed zone.

Local X-ray spectral microanalysis and scanning in the characteristic emission of the corresponding elements established that the alloying elements in the laser thermochemical treatment zones are distributed uniformly (Figure 3(b)). The content of alloying elements-from 5\% to 17\%.

We determined the phase composition of the steels by X-ray diffraction analysis after alloying with the investigated nitride-forming elements. In low-carbon steel in the laser thermochemical treatment zones a solid solution is formed with substitution of the alloying elements at $\alpha$-Fe, and in high-carbon steels except solid solution fine carbides of alloying elements are formed. 
Upon alloying continuous conditions, there is $15 \%$ - 17\% each of $\mathrm{Cr}$ and $\mathrm{V}$ in the laser zone. The molibdenum concentration in the laser zone is $8 \%$. On the diffraction patterns taken from the surface of the alloying zone, we observed the intermetallides FeMo and $\mathrm{Fe}_{7} \mathrm{Mo}_{6}$. We explain the very significant increase in hardness of the surface upon alloying with molibdenum by the formation of the intermetallide phases. The Al concentration in the laser zone is no greater than $5 \%$. Upon dissolution of $\mathrm{Al}$ in the alloying zone, a substitution solid solution formed. By metallographic analysis, we established optimal velocities an extremely fine-grained structure of alloyed ferrite obtained in the surface layer, and cellular equated grains occupy the greater part of the volume. As we approach the boundary with the matrix, the grains become columnar, oriented along the direction of maximum heat withdrawal (Figure 3(a)). We should note that the greatest decrease in grain size observed in alloying with molybdenum, and the least decrease observed with vanadium.

The microhardness in the laser alloying zones distributed uniformly and for continuous alloying conditions from 3000 to 12,000 MPa in low-carbon steels, and from 8000 to 15,000 MPa in high-carbon steels.

The disadvantage of laser treatment, especially in high-carbon steel, is the high tensile stresses under the zone of laser treatment, that reduce the characteristics of crack. Therefore, the heating in the nitriding has positive effects on these properties. After laser, alloying nitriding in industrial furnaces according to standard regimes carried out. Figure 4 shows the formation of the modified layer on the steel surface.

After laser alloying and brief nitriding $\left(t=570^{\circ} \mathrm{C}, \mathrm{r}=4.5 \mathrm{~h}\right)$ of low-carbon steels the maximum microhardness is observed in zones alloyed by aluminium-2000 $\mathrm{H}$. Nitriding of the surface of steel alloyed with $\mathrm{Cr}$, $\mathrm{V}$, and Mo under analogous conditions leads to formation of hardness layers with a smooth decrease in microhardness along the thickness $1200-1800 \mathrm{H}$. Nitriding at $540^{\circ} \mathrm{C}$ for $29 \mathrm{~h}$ allows us to obtain hardened zones of thickness up to $560 \mu \mathrm{m}$ with a uniform distribution of microhardness (Figure 5).

Efficiency of the combined treatment of high carbon steel is slightly lower, because after nitriding formed carbonitrides of alloying elements, which have a lower hardness than nitrides.

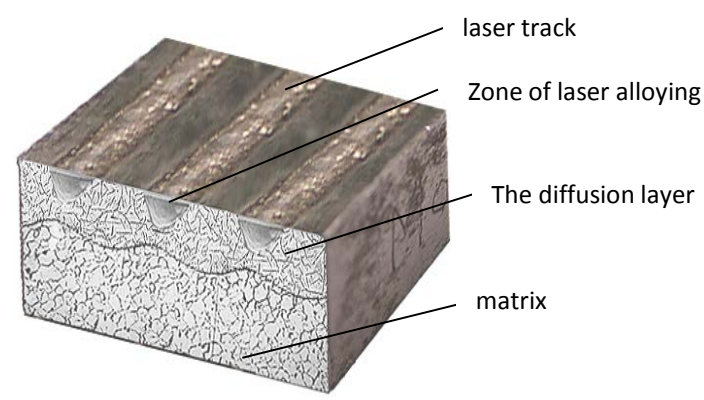

Figure 4. The formation of the modified layer on the steel surface.

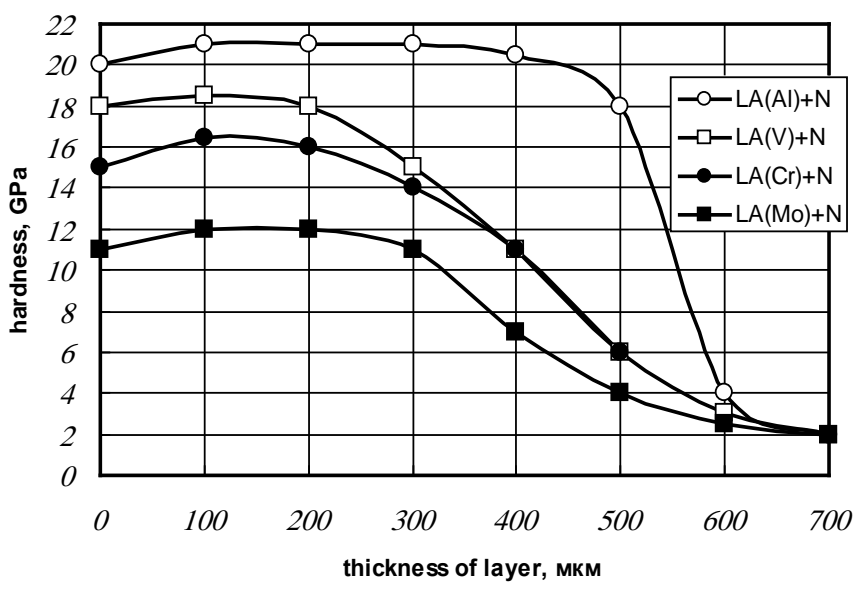

Figure 5. Distribution of hardness in laser alloyed zones of steel 20 $(0.2 \% \mathrm{C})$ after laser alloying and nitriding. 
When studying the stress state of a surface strengthened by a combined treatment, we established the positive role of nitriding in the distribution of residual stresses. In the nitriding process, the surface of the zone of laser effect subjected to a double action. On one hand, it saturated with nitrogen, which causes substantial volume changes and, as a consequence, the formation of additional internal residual stresses. On the other hand, the additional temperature effect accompanied by diminishing of the residual tensile stresses that appear in the process of laser alloying. The study has shown that nitriding decreases the level of the compressive stresses on the surface of the zone of laser effect and, with the appearance of tensile stresses outside the zone of laser effect, changes their sign to the opposite (Figure 6). Thus, a result of the combined treatment the residual compressive stresses formed on the surface of the specimens are inconsiderable.

As a result of lengthy wear-resistance tests we established that the wear resistance of low-carbon steel treated according to the combination technology is 15 times higher than the wear resistance of nitrided steel 20, and 1.5 - 3 times higher than the wear resistance of commercial steel $38 \times 2 \mathrm{MHA}(0.38 \% \mathrm{C}, 2 \% \mathrm{Cr}, 1 \% \mathrm{Mo}, 1 \%$ $\mathrm{Al}, 0.025 \% \mathrm{~S}, 0.025 \% \mathrm{P}$ ) nitrided under analogous conditions. Enhancement of the wear resistance under dry friction condition is due to the high microhardness zones (up to 20,000 MPa) and formation of a relief pattern on the surface of Charpy type. The highest wear resistance achieved by alloying the steel surface with aluminum followed by nitriding.

Investigation of the resistance of steel to propagation of a fatigue crack after combination treatment showed that upon deposition of nonoverlapping tracks by laser thermochemical treatment followed by nitriding, its crack resistance increased by a factor of 1.5. The kinetic diagrams in this case have an unusual shape, which however completely corresponds to the mechanism of fatigue fracture of such heterophase samples. We observe unstable propagation of the fatigue crack: acceleration alternates with periodic retardation. Fractographic studies allowed us to establish the mechanism for fracture of the metal in the laser zone. When the tip of the mainline crack reaches the heat-affected zone, its velocity markedly decreases. At the same time, within the interior of the sample the fatigue crack continues to propagate at practically the same velocity as before, and consequently deformation of the crack front occurs. When the crack propagates to approximately the middle of the track, brittle fracture of the melting zone occurs; and upon further propagation of the crack, the neck breaks according to a mixed mechanism. A characteristic feature of fracture of samples with overlapping tracks from laser thermochemical treatment is formation of strongly extended secondary cracks and pore-like defects of significant dimensions, located parallel to the surface of the sample at a distance equal to the thickness of the alloying zone. Nitriding such a surface promotes suppression of pore formation and localization of the fracture process, especially in the melting zone, where we no longer observe extended regions of brittle fracture, which especially connected with the presence of dispersed nitrides.

Combination treatment enhances the heat resistance of the hardened alloys up to $600^{\circ} \mathrm{C}$ upon introduction of $\mathrm{V}, \mathrm{Cr}, \mathrm{Mo}$ as alloying elements and can be effectively used to increase the wear resistance of parts operating under sliding friction conditions at elevated temperatures. The microhardness of the hardened layers increased, which connected with the increase of the amount of segregated dispersed nitrides in dispersed form. Heating the nitrided surface pre-alloyed with aluminum leads to softening.

For hardening of large parts, such as slide tails and other supporting parts of machines, we recommend that continuous lasers used. In this case, the alloyed layers have significant thickness, which requires prolonged nitriding. Parts of low-carbon high-grade steel, treated according to the combination technology, can support contact loads and operate under abrasive and fatigue conditions at high temperatures and in aggressive media. The

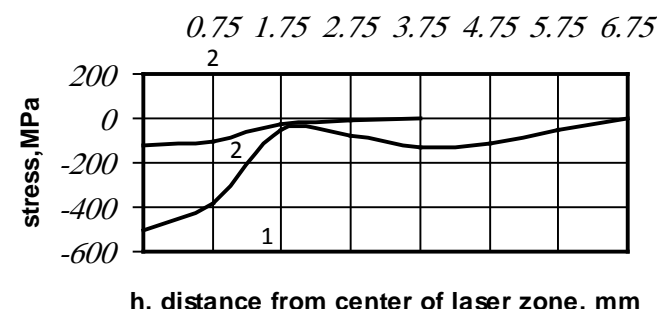

Figure 6. Distribution of residual stresses on the surface of steel $20(0.2 \% \mathrm{C})$ in a direction perpendicular to the laser track: 1 -laser alloying; 2 -combined treatment. 
best characteristics for cyclic-loading crack resistance achieved by combination treatment upon alloying with chromium and vanadium with non-overlapping tracks during laser thermochemical treatment.

\subsection{Two-Stage Technology of Metallization by Laser and Furnace Heating of Constructional Steels}

A well-known process of thermodiffusional metallization has a positive effect on hardness, wear resistance, corrosion resistance, contact fatigue, fatigue resistance and other properties of products. However, essential lacks of such process are high temperature $1050^{\circ} \mathrm{C}-1420^{\circ} \mathrm{C}$ and long duration of the process. In order to get modified layer with thickness 100 microns processes carried out at a temperature for a minimum 6 - 8 hours.

With a view to increase the efficiency of metallization steel surface, we proposed the two-stage process. The first stage is the local laser alloying in pulsed radiation. The second stage- the thermodiffusion metallization in the furnace in an atmosphere of ammonia.

Saturation from the coating with halides, such as $\mathrm{FeCl}_{2}$, carried out. Zones of laser alloying are an additional source of the alloying elements, which diffuse both on the surface and into the sample.

Presence of nitrogen in the saturation atmosphere decreases the temperature of polymorphic $\alpha \rightarrow \gamma$ transformation, and reduces the temperature of the process to $700^{\circ} \mathrm{C}$. Halide $\mathrm{CrCl}_{2}$, located in the coating is the catalyst of transport reactions, reduces the duration of the saturation up to 3 hours. When heating on the steel surface reaction takes place: $\mathrm{CrCl}_{2}+\mathrm{Fe} \leftrightarrow \mathrm{Cr}+\mathrm{FeCl}_{2} \uparrow$. As a result, the surface of the detail saturates with the alloying element, the diffusion starts from the zones of laser alloying and goes both on the surface and in depth detail that allows receiving a diffusion layer on the entire surface, regardless of complexity of the geometry.

Investigations carried out on the samples from iron and steel $40 \times(0.4 \% \mathrm{C}, 1 \% \mathrm{Cr})$, surface was saturated with chromium, titanium and aluminum.

Technological parameters of two-stage technology are parameters of the laser alloying: the radiation power, the thickness of alloying suspension and the number of laser "spots" on the surface, the parameters of the thermodiffusion metallization: temperature, length of the process and composition of atmosphere.

On the thickness of the metallized layer is greatly influenced the number of laser "spots" on the treated surface. Investigations have shown that in the absence of laser zone thickness of the hardened layer after metallization is 40 microns. If the filling of surface by laser spots is $4 / \mathrm{sm}^{2}$ zones, the thickness of the metallized layer is 80 microns, while increasing the density of the laser "spots" to 6/sm² -increased to 120 microns. On further increase of this parameter increase the thickness of the hardened layer is negligible. After a standard metallization in furnace diffusion, layer thickness is less than 40 microns, and after two-stage metallization by laser and furnace heating-100 microns.

Figure 7 presents the distribution of microhardness inside the zone of laser treatment (curve 2) and beyond it (curve 1). Seen that the hardness of the diffusion layers metallized with preliminary laser treatment and without it differs insignificantly and is $4500-5000 \mathrm{MPa}$. In any case, the microhardness on the surface in 2 - 3 times higher than in the core.

Researches of influence of two-stage chroming of steel $40 \times(0.4 \% \mathrm{C}, 1 \% \mathrm{Cr})$ on the thickness and microhardness of the modified layer have shown that increasing the duration of the thermodiffusion saturation from 3 to 4 hours the thickness increases from 100 microns to 120 microns. Further increasing the duration up to 7 hours increases thickness of the layer only 20 microns. The optimal parameters for two-stage saturation with $\mathrm{Cr}$ : $\mathrm{T}=700$ $\div 800^{\circ} \mathrm{C}, \tau=3 \div 4$ hours, with $\mathrm{Ti}: \mathrm{T}=750^{\circ} \mathrm{C}, \tau=4$ hours; with $\mathrm{V}-\mathrm{T}=735^{\circ} \mathrm{C}, \tau-3$ hours; with $\mathrm{Al}-\mathrm{T}=700^{\circ} \mathrm{C}$, $\tau-2$ hours.

During the two-stage treatment of steel $40 \times$ chroming layer with thickness up to 100 microns formed. However, the thickness of the metallized layer, obtained by the standard technology without laser alloying, is less than 40 microns. Figure 8 shows that microhardness of the metallized layer with preliminary laser treatment and without it differs insignificantly and is $12,000-13,000 \mathrm{MPa}$, which is comparable with the hardness of high-alloy steel after nitriding.

The thickness of the effective hardening with hardness above $4000 \mathrm{MPa}$ is about 120 microns in the first case (Figure 8, curve 2) compared with 60 microns in the other (Figure 8, curve 1).

\section{Conclusions}

1) Two combined technologies were proposed with the use of laser energy: first-laser alloying by nitride- 


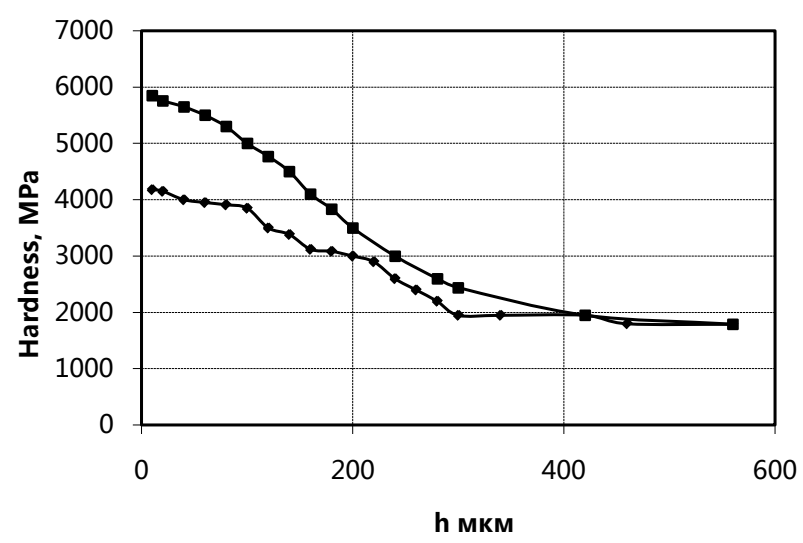

Figure 7. Distribution of microhardness in thickness after metallization of iron by chromium $\left(\mathrm{T}=735^{\circ} \mathrm{C}, \tau=3 \mathrm{~h}\right)$ : 1 - outside the laser zone, 2 -inside the laser zone.

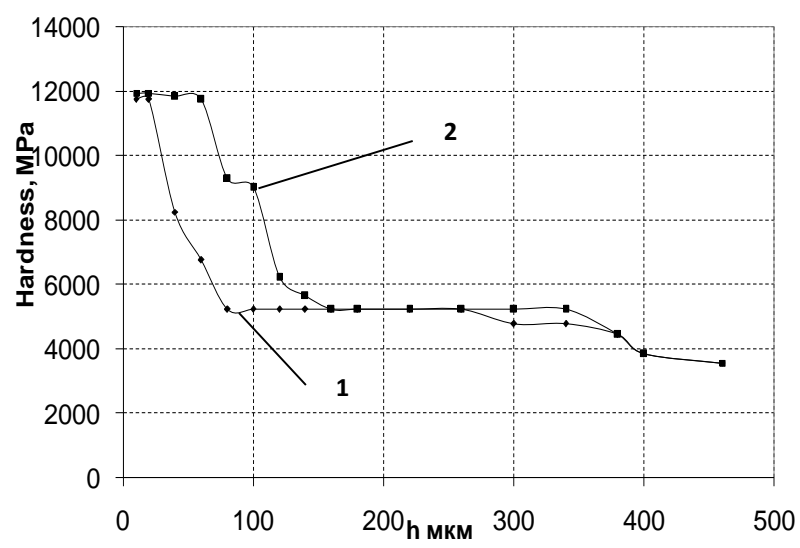

Figure 8. Distribution of microhardness over the thickness of steel 40×: 1 -after the standard metallization without laser alloying $\left(\mathrm{T}=1000^{\circ} \mathrm{C}, \tau=3 \mathrm{~h}\right), 2$-after a two-stage treatment $\left(\mathrm{T}=735^{\circ} \mathrm{C}, \tau=3 \mathrm{~h}\right)$.

forming elements followed by nitriding, and second—-the local laser alloying followed by metallization in atmosphere of ammonia.

2) It is shown that laser alloying in continuous radiation forms a layer with a homogeneous fine-grained structure with thickness of 600 microns. The subsequent nitriding increases the microhardness of the surface layer of low-carbon steels to $2000 \mathrm{H}$, and increases wear-resistance in a 3 - 15 times and crack resistance in a 1.5 times.

3) Two-stage technology of metallization allows getting diffusion layer on the surface of steels with the thickness, which is 1.5 - 2 times higher than that after traditional metallization. In addition, this method of surface modification can significantly reduce the temperature of diffusion metallization and reduce the processing time to 3 hours. The optimal regimes of both technologies, which provide homogeneous multiphase diffusion layers with high hardness and wear resistance, were determined.

4) The mechanism of improving the efficiency of thermodiffusion metallization defined: zones of laser alloying are an additional source of the alloying elements, which diffuse both on the surface and into the sample. Presence of nitrogen in the saturation atmosphere decreases the temperature of polymorphic $\alpha \rightarrow \gamma$ transformation, and reduces the temperature of the process to $700^{\circ} \mathrm{C}$. Halide $\mathrm{CrCl}_{2}$, located in the coating, is the catalyst of transport reactions; it reduces the duration of the saturation up to 3 hours.

\section{References}

[1] Rykalin, N.N., Uglov, A.A., Zuev, I.V. and Kokora, A.N. (1985) Laser and Electron Beam Treatment of Materials: 
Handbook. Mashinostroenie, Moscow, 496.

[2] Chudina, O.V. and Brezhnev, A.A. (2010) Surface Alloying of Carbon Steels by Laser Heating. Strengthening Technologies and Coatings, No. 4, 10-16.

[3] Solind, A., De Sanctis, M., Paganini, L., et al. (1984) Origin and Development of Residual Stresses Induced by Laser Surface-Hardening Treatments. Journal of Heat Treating, 3, 193-204. http://dx.doi.org/10.1007/BF02833261

[4] Grigoryan, A.G., Safonov, A.N., Mayorov, V.S., Baskov, A.F. and Ivashov, G.P. (1987) Distribution of Residual Stresses on the Surface of Steel Hardened by Continuous $\mathrm{CO}_{2}$ Laser. Metallovedenie i Termicheskaya Obrabotka Metallov, 9, 45-49.

[5] Brover, A.V. (2005) Effect of Surface Heat Treatment Using of Concentrated Energy Flows on the Structural Strength of Steel. Strengthening Technology and Coatings, 4, 22-25. 
Scientific Research Publishing (SCIRP) is one of the largest Open Access journal publishers. It is currently publishing more than 200 open access, online, peer-reviewed journals covering a wide range of academic disciplines. SCIRP serves the worldwide academic communities and contributes to the progress and application of science with its publication.

Other selected journals from SCIRP are listed as below. Submit your manuscript to us via either submit@scirp.org or Online Submission Portal.
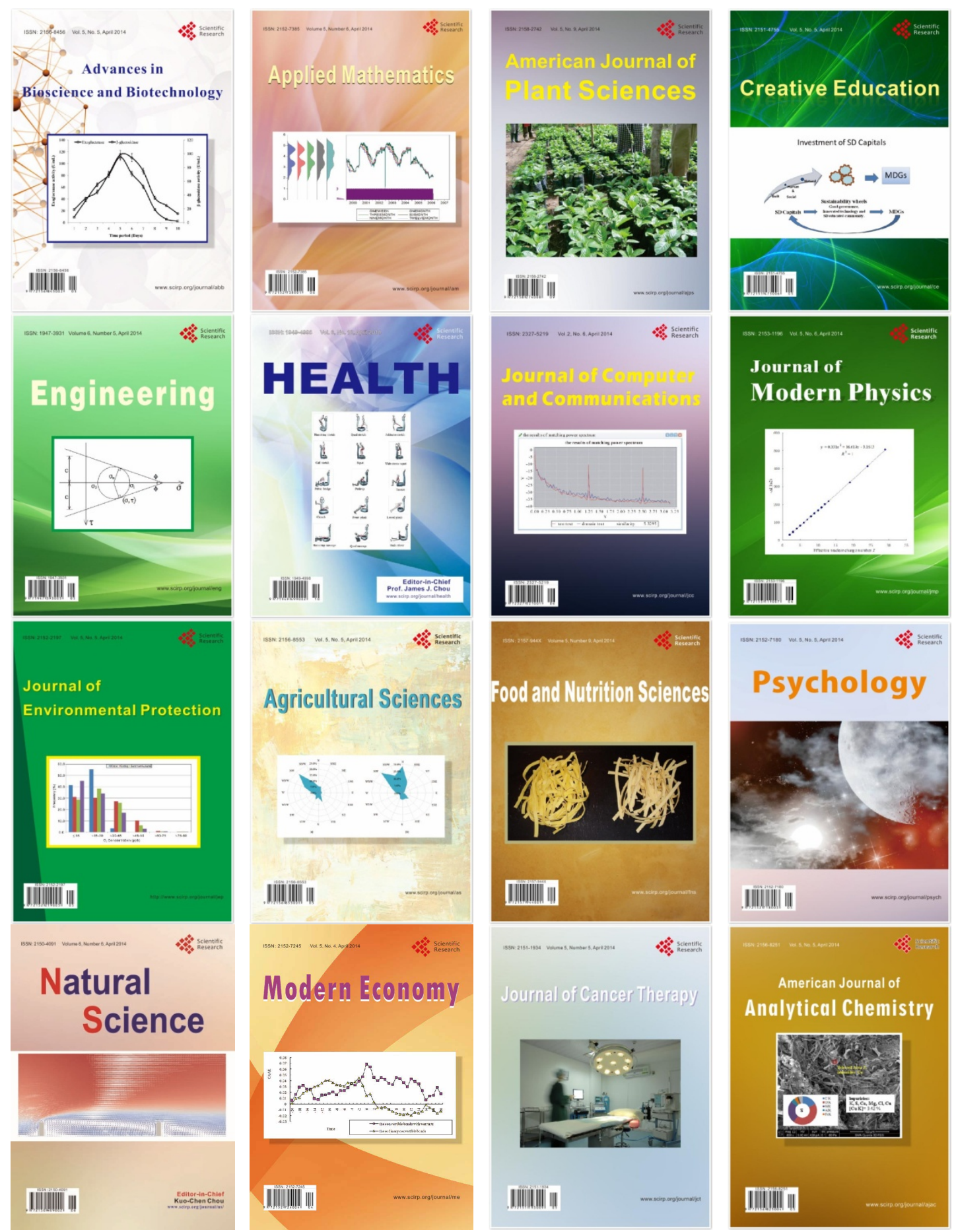